\title{
Nacionalismo y Reforma Universitaria en el siglo XX argentino. Una mirada desde su cuna: Córdoba, 1918
}

\section{Nationalism and University Reform in Argentine during $X X$ century. A look from its birth: Córdoba, 1918}

\author{
CésarTcach \\ Consejo Nacional de Investigaciones Científicas y Técnicas \\ Universidad Nacional de Córdoba \\ cesartcach@gmail.com \\ (Argentina) \\ María Clara Iribarne \\ Universidad Nacional de Córdoba \\ Centro de Estudios Avanzados \\ claireiribarne@gmail.com
}

(Argentina)

\section{Resumen}

Este artículo ofrece una reconstrucción histórica de la relación entre nacionalismo y reformismo a partir de un doble registro: el de las concepciones presentes en el universo cultural reformista y el de las posiciones y las prácticas asumidas por el peronismo y espacios políticos nacionalistas. En función de este hilo conductor, se analizan las posiciones del nacionalismo popular, del nacionalismo católico, del peronismo histórico y de diversas expresiones de derecha como las expresadas en las revistas El Caudillo de la Tercera Posición, Leña y Marchar. Se trata de demostrar que el nacionalismo, construyó su posición anti-reformista en cuatro registros que descansaron en un sustrato común: la defensa de una tradición que exaltaba a la Iglesia y al Ejército como los fundadores de la Patria (clave tradicionalista); la contraposición entre las masas y los sectores medios que habían gestado la Reforma (clave plebeya); el anti-intelectualismo (clave xenófoba que se vinculaba a la denuncia de lo extranjero), y el imperativo de incluir a las universidades en un entramado organicista marcado por el primado de la cohesión, la "Comunidad Organizada" (clave peronista). El común denomi- 
nador que asociaba estas cuatro miradas era el antiliberalismo, en el sentido político-cultural de la expresión.

Palabras Clave: Reforma Universitaria, nacionalismo; catolicismo, peronismo, movimiento estudiantil

\begin{abstract}
The article offers a historical reconstruction of the relationship between nationalism and university reformism focusing two aspects: on the one hand, the reformist cultural universe, and on the other, the positions and practices assumed by peronism and nationalist political spaces. With this aim we analyze the positions of "popular nationalism", Catholic nationalism, historical peronism and various expressions of the right-wing such as those expressed in the reviews El Caudillo de la Tercera Posición, Leña and Marchar. The article hypothesis is that nationalism built its anti-reformist position in four registers that remain as a common substratum: the defense of a tradition that exalted the Church and the Army as the founders of the Homeland (traditionalist key); the contrast between the middle sectors that had given birth to the University Reform and the masses (plebeian key); the anti-intellectualism (xenophobic key that was linked to the denunciation of the foreign); and the imperative to include universities in an organicist framework marked by the primacy of cohesion, called the "Organized Community" (peronist key). The common denominator that associated these four explanations was anti-liberalism, in the political-cultural sense of the expression.
\end{abstract}

Keywords: University Reform, nationalism, catholicism, peronism, student movement

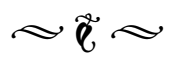

\section{Introducción}

Esta investigación tiene por objeto el estudio de las afinidades y contrastes, relaciones de continuidad, contigüidad o ruptura, entre los universos culturales y posicionamientos políticos del nacionalismo argentino, en sus diversas vertientes, y el proveniente de los valores y representaciones asumidos o forjados a partir del levantamiento estudiantil cordobés de 1918.

A tenor de estas preocupaciones, se examinan diversas vetas de pensamiento que confluyeron en la formación de la matriz originaria del movimiento reformista y su dinámica relacional con las fuerzas nacionalistas a lo largo de una parte sustantiva del siglo XX: desde la gestación del reformismo (1918-19) hasta el golpe militar de 1976.

\section{El americanismo}

¿El reformismo universitario que recorrió América Latina durante la primera mitad del siglo veinte, fue un movimiento nacionalista? El aleph en el sentido de la literatura borgeana, es decir el punto desde el cual los contestatarios de 1918 se asomaban para contemplar e 
interpretar el mundo -su cosmovisión- distaba de parapetarse en los marcos de la nacionalidad argentina. En los textos, discursos, proclamas y apelaciones de los inspiradores de la Reforma Universitaria de Córdoba, la unidad de análisis no era el Estado nacional sino América: una noción genérica que admitía diversas voces y matices. El ideal americanista podría expresarse con el vocablo América Latina -"generosa y latina" decía Deodoro Roca en su tesis doctoral de 1915-, Sudamérica como se indicaba en el manifiesto fundante de la Reforma Universitaria, Iberoamérica o América Ibérica para incluir a Brasil, como se señalaba en el manifiesto de los intelectuales cordobeses agrupados en la Unión Latinoamericana en 1928 o en el Congreso Iberoamericano de estudiantes celebrado en México en 1931, llegando a postularse la necesidad de una ciudadanía ibero-americana.

Concomitantemente, se produjo el rescate cultural de las civilizaciones precolombinas. $\mathrm{La}$ elección del lugar del Primer Congreso $\mathrm{Na}^{-}$ cional de Estudiantes del Perú celebrado en 1920 fue sintomática: las alturas del mítico y místico Cusco. Así, se desbrozó el camino a la noción de Indoamérica, aunque su uso fue mucho más limitado en los países del cono sur: en Argentina, Chile y Uruguay relacionado con el peso del componente migratorio europeo, en Brasil con la relevancia de sus raíces negras y africanas. Esta noción suponía una visión acerbamente crítica de la colonización española. Ella convivió, empero, con otros filones de pensamiento que reivindicaban un hispanismo democratizador: desde los comuneros de Castilla del siglo XVI que desafiaban el absolutismo monárquico hasta los liberales españoles del siglo XIX. Ambas vetas estuvieron presentes en los escritos de los reformistas. En el balance, empero, si bien Saúl Taborda (1918) destacó la relevancia de "la entraña viva de la hispanidad"(p.69), en la formación de la identidad nacional y Deodoro Roca (2006) hizo referencia una América hispana contrapuesta a la plutocracia típica del mundo anglosajón (p. 40); tendió a primar una mirada histórica que condenaba al colonialismo y el dogmatismo religioso, al poder del Trono y la Cruz. Varios años después, la proclamación de la República Española primero y la guerra civil después, encendió una caldera de pasiones solidarias y marcó el re-encuentro del universo cultural reformista con lo que se concebía como lo mejor de la tradición española,

A tenor de lo expuesto, es lícito preguntarse $¿$ El ideal americanista aspiraba a superar el corsé de los estados nacionales y por consiguiente de los nacionalismos, para imaginar una identidad supranacional? Ciertamente, este filón de pensamiento estaba presente en el principal ideólogo del reformismo universitario. Deodoro Roca exclamaba en 1918: ¡Crear hombres y hombres americanos es la recia imposición de esta hora!" y diez años más tarde insistía: "una nueva nacionalidad supraterritorial ideal (...) acusa tenue perfil" y su "fuerza fecundante (...) deja en los labios gusto a barro creador" (Roca, 2006, pp. 35-46).

De Sandino en Nicaragua y la experiencia de la revolución mexicana hasta las acciones concretas de solidaridad con las luchas sociales urbanas en el cono sur del continente, el ideal americanista se potenciaba como contracara del panamericanismo propuesto desde Washington, al que se consideraba inspirado por la doctrina Monroe. ${ }^{1}$ Si bien el líder intelectual de la Reforma de Córdoba no hizo alusión

1. James Monroe, presidente de los EE.UU entre 1817-1825, al que se le atribuyó un célebre principio legitimador del imperialismo norteamericano: "América para los americanos" (del norte). 
explícita a una "Patria Grande" latinoamericana, coincidió con otros intelectuales relevantes -como el porteño Manuel Ugarte- que los nacionalismos locales eran insuficientes para enfrentar al imperialismo, razón por la cual era menester una propuesta de carácter continental (Moyano, 2004).

El desencanto, el miedo y el escepticismo cobijado a la sombra de la quiebra de certezas generada por la primera guerra mundial fue resignificada en América Latina al calor del influjo del antiimperialismo ético espiritualista de las nuevas vanguardias estéticas, desde el nicaragüense Rubén Darío (El triunfo de Caliban de 1898) hasta el uruguayo José Enrique Rodó (Ariel de 1910) y el cordobés Saúl Taborda. Este último, referente intelectual de los protagonistas de la Reforma Universitaria, denunciaba en sus Reflexiones sobre el ideal politico de América (1918) el rol imperialista de los Estados Unidos en México y América Central (Taborda, 1918; Roitenburd, 2007). Su crítica del imperialismo -en una época en que los marines norteamericanos hacían sentir su influencia en Nicaragua, Haití y Santo Domingo- se asociaba a la exaltación de una espiritualidad genérica y genuinamente "americana", opuesta y superadora de los valores predominantes en Europa. Esta mirada suponía una concepción por la cual se contraponía la presunta decadencia europea con el futuro luminoso de América Latina. América, pues, debía rectificar a Europa: revisar, corregir, desechar o transmutar sus valores.

Empero, el americanismo presente en el universo cultural reformista permanecía abierto a las experiencias de otras latitudes. Así, atento a la revolución rusa de octubre de 1917, un artículo alusivo de La Gaceta Universitaria - el periódico de los estudiantes de la Refor- ma-destacaba, por ejemplo, el papel del escritor Máximo Gorki como ministro de Instruc-

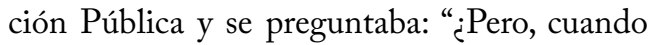
llegaremos a tener nosotros un ministro de educación como el novelista ruso?”, y explicaba el nuevo rol de los higienistas-pedagogos en la "educación sexual" de las nuevas generaciones en la Rusia socialista. Destacaba, asimismo, que las mujeres tenían los mismos derechos civiles y políticos que los hombres, y añadía:

"La vieja institución del matrimonio no es obligatoria. Existe una amplia libertad de cultos y se registran diariamente un gran número de casamientos por las iglesias Ortodoxa Rusa, Protestante, Católica-Judía, no teniendo el Estado socialista ninguna clase de intromisión en estos asuntos privados. Las uniones de cualquier género quedan fácilmente rotas cuando uno de los contrayentes así lo desea, vale decir, existe el divorcio absoluto". ${ }^{2}$

En otras palabras, la lectura que se hacía de la revolución rusa era en clave liberal democrática.

\section{El reformismo en tiempos de guerra: entre las críticas de FORJA, el militarismo autoritario y el nacionalismo católico.}

En 1930 un golpe militar derrocó al presidente radical Hipólito Yrigoyen, iniciándose un período de fraudes electorales, asfixia de las libertades públicas y represión política que se extendió durante trece años. En 1943, otro golpe militar, promovido por oficiales nacio-

2. (18 de agosto de 1918). La Gaceta Universitaria ( $L G U$ ) 19, p. 6. Archivo del Museo de la Reforma Universitaria (AMRU), Córdoba. 
nalistas prometió poner fin a esa situación, pero las universidades fueron entregadas a interventores pertenecientes a la derecha nacionalista católica y/o filo-fascista: Giordano Bruno Genta en la Universidad del Litoral, Tomás Casares en la Universidad de Buenos Aires, Santiago de Estrada en la Universidad de Tucumán, Lisardo Novillo Saravia en la de Córdoba. El clima represivo, la persecución ideológica, las cesantías de profesores -entre ellas la del prestigioso Bernardo Houssay en la UBA- y la imposición de la enseñanza religiosa obligatoria en las escuelas, provocaron la inmediata oposición del movimiento reformista. Por el contrario, el diario del Arzobispado cordobés exhortaba a tener fe "en las virtudes permanentes de la nacionalidad, tantas veces reflejadas en la acción heroica de las Fuerzas Armadas", convencido que había llegado la hora de poner punto final a cualquier esbozo de laicismo en el plano educacional. ${ }^{3} \mathrm{El}$ matutino católico intentaba afianzar en la sociedad cordobesa un relato acerca del origen de la violencia en la universidad que tenía su punto de partida en 1918:

Este fenómeno se definió entre nosotros el año 1918. No queremos decir que no existiera antes, sino que fue entonces cuando la violencia irrumpió en la Universidad para desarticularla, para transformarla en obligado campo de combate de todas las experiencias sociales. ${ }^{4}$

Esta idea de la Reforma Universitaria como semilla del mal, de la subversión y la corrup-

3. Editorial (11 de mayo de 1945). Los Principios (LP)

Hemeroteca de la Legislatura de Córdoba (HLC), Córdoba; Editorial (11 de mayo de 1945). Córdoba (CBA). Círculo Sindical de la Prensa de Córdoba, Córdoba.

4. Editorial: La violencia en la universidad. (13 de junio de 1945). LP. ción de las costumbres, no fue compartida por la Fuerza de Orientación Radical de la Joven Argentina (en adelante FORJA), agrupación de intelectuales nacionalistas de origen yrigoyenista que contó entre sus filas a figuras influyentes de la cultura argentina como Luis Dellepiane, Arturo Jauretche, y Gabriel del Mazo. Surgida en 1935, repudiaba el golpe de 1930 pero también las complicidades de la dirección del partido radical-en manos del alvearismo- con el orden conservador. Sus posiciones, identificadas con un nacionalismo popular antitético del nacionalismo católico y del fascismo, pero también de las políticas imperialistas de Gran Bretaña y los EE.UU, reivindicaban el legado de la Reforma al tiempo que criticaban sus limitaciones. Un documento de 1939, señalaba la necesidad de lucha por una universidad democrática y progresista al servicio de las necesidades del pueblo, al tiempo que destacaba como objetivo: "Por la Reforma Universitaria como parte de la Emancipación Nacional' (Hernández Arregui, 1973, p. 370).

La postura de FORJA ante la Reforma de 1918, si bien minoritaria en el marco de las impetuosas oleadas del nacionalismo autoritario de los años treinta, intentaba proyectar una mirada crítica y autocrítica de la experiencia reformista. Cuestionaba a quienes intentaron liquidar "todo intento de democratización y modernización de la universidad" y recordaba que su finalidad había sido romper una "muralla inexpugnable de la clase conservadora argentina y de los restos de la antigua cultura eclesiástica”. Sin embargo, añadía, la oligarquía explotó sus contradicciones internas y "neutralizó todo lo que de revolucionario y popular albergaba” (Hernández Arregui, 1973, p. 367).

En rigor, FORJA, veía en el remozamiento ideológico de la Reforma, una auténtica vía de 
liberación nacional y latinoamericana, pero en contraste con el ideario antimilitarista del '18, asociaba la acción reformista a la fusión del pueblo con el Ejército. Pese a ello, tras la revolución de junio de 1943, el presidente, general Pedro Pablo Ramírez encarceló a la plana mayor de FORJA, incluido al reconocido escritor Arturo Jauretche.

En octubre de 1943, uno de los referentes intelectuales más importantes del nacionalismo católico y activo difusor del franquismo y la judeo-fobia, Gustavo Martínez Zuviría, asumió como ministro de Justicia e Instrucción Pública del gobierno militar. La Federación Universitaria Argentina (FUA) no tardaría en ser ilegalizada. Ese mismo mes, numerosos profesores de la UNC fueron cesanteados por haber firmado una declaración que criticaba la política exterior del gobierno del general $\mathrm{Ra}-$ mírez. Los docentes -en consonancia con las posturas de las agrupaciones estudiantiles- habían hecho público un documento de repudio al nazifascismo y exigían un posicionamiento firme del gobierno (en el que predominaban las tendencias germanófilas), empeñado en mantener la neutralidad en el conflicto. La identidad política de los docentes cesanteados era diversa: su común denominador era el antifascismo.

El 2 de noviembre de 1943, los estudiantes reformistas de todas las tendencias políticas - unificados en torno al "Comando Único de Coordinación Estudiantil” -en sustitución provisoria de la Federación Universitaria de Córdoba (en adelante, FUC), golpeada por la represión y las restricciones a su accionar- dieron a conocer un manifiesto cuya retórica permitía evocar el Manifiesto Liminar de 1918. Titulado, "Para que todos sepan: hablan los estudiantes de Córdoba", dibujaba un retrato del "novísimo ministro" en éstos términos:

Hugo Wast no tiene derecho a hablarnos a nosotros. El pertenece a aquellos transhumantes personajes que se amparan en cada etapa bajo el rescoldo de un nuevo dispensador de mercedes. Le falta autoridad moral (...). Difamador profesional y hombrecillo sibilino es el totalitario embozado que ante el apoyo circunstancial de unas bayonetas y de unos gritos cuarteleros, siente revivir su escondida vocación de pequeño dictador. ${ }^{5}$

El manifiesto estudiantil aseguraba que las huelgas dejarían vacíos los hospitales, los gabinetes, las aulas y los anfiteatros en defensa de los docentes expulsados. Y otorgaba también un papel a las mujeres en la lucha contra el ministro ícono del nacionalismo de derecha: "Y junto a nosotros, estarán las compañeras para alentarnos con su sonrisa, para reconfortarnos con su presencia, para fortalecernos con su palabra". ${ }^{6}$ En este punto referido al protagonismo de las mujeres, el documento recuperaba a contragusto de los nacionalistas un aspecto presente en el movimiento de 1918-1919. Durante ese bienio, las promotoras cordobesas de los derechos de la mujer ya empleaban el término feminismo y el periódico de los estudiantes cordobeses La Gaceta Universitaria cedía sus páginas a la publicación de la Asociación Feminista Nacional. Influían al respecto, María Ofelia Grandoli y Ana Mori, líderes del Comité Femenino Córdoba Libre (Tcach, 2008; Bustelo, 2018).

5. Para que todos sepan: hablan los estudiantes de Córdoba, 2 de noviembre de 1943, caja 13, folios 86-87, 1943. Archivo Intermedio (AI). Archivo General de la Nación (AGN), Buenos Aires.

6. Para que todos sepan: hablan los estudiantes de Córdoba, 2 de noviembre de 1943, caja 13, folios 86-87, AI. AGN, Buenos Aires. 
En diciembre de 1943, una nueva afrenta al ideario reformista se concretó con la imposición de la enseñanza religiosa obligatoria en las escuelas públicas. El nacionalismo católico estaba de fiesta y los ecos de su algarabía se confundían en una sinfonía de voces nacionalistas y autoritarias cuyas espadas mayores eran la Iglesia Católica y el Ejército.

Con motivo de la caída de Berlín, en mayo de 1945, miles de estudiantes y militantes antifascistas celebraron jubilosamente en las calles de Córdoba el fin del régimen nazi. La represión de que fueron objeto era descripta por la FUC en estos términos: "sorprendentemente (...) cuando hombres, mujeres y niños se aprestaban a llevar a la intimidad de sus hogares la alegría colectiva (...) fueron vandálicamente atropellados y apaleados por las fuerzas policiales". ${ }^{7} \mathrm{La}$ nómina de detenidos incluía a algunos ilustres reformistas como Gregorio Bermann y Enrique Zanni. La justicia no hizo lugar a los pedidos de habeas corpus.

\section{El duelo peronismo-reformismo}

En el universo cultural del coronel que ganó las elecciones de febrero de 1946 -Juan Domingo Perón- el principio de la comunidad organizada -un todo orgánico en que las diversas partes se articulan armoniosamente como las piezas de un rompecabezas- suponía la primacía de la unidad sobre la diversidad. Esta cohesión -garantizada por la conducción política de un líder carismático- debía partir de la cima del Estado para extenderse hasta los últimos rincones societales. A contraviento del universo cultural de la Reforma, jalonada por vetas radicales, marxistas, anarquistas, liberales

7. (12 de mayo de 1945). CBA. Córdoba. y masonas, la cultura política peronista partía del ineludible imperativo de eliminar no solo la autonomía relativa de las universidades en el campo institucional, sino también echar por tierra con la independencia política de estudiantes y docentes. En otras palabras, suponía el paso de la polifonía de las ideas a la celebración de un discurso único que rendía tributo al líder que tenía en sus manos la conducción de sus instituciones, incluida la propia universidad.

Para comprender la intensidad de esta vocación hegemónica, debe tenerse presente que la idea de comunidad organizada se asociaba a la de movimiento nacional. Éste, como expresión totalizadora del pueblo argentino- debía descansar en un conjunto de actores colectivos organizados, con una indisimulable impronta estatal (Tcach, 2016). Las universidades, pues, debían estar encuadradas en un sedicente movimiento nacional cuyo liderazgo político no solo era incuestionable sino su expresión más acabada en el plano simbólico. Era este imperativo el que legitimaba la discriminación ideológica y la represión política.

A tenor de lo expuesto, no ha de extrañar que los dos primeros años de gobierno peronista estuviesen marcados por su duelo con el movimiento estudiantil. Tres ejes de conflicto adquirieron centralidad: la intervención a las universidades, el proyecto de ley universitaria gestado por el oficialismo y los despidos de centenares de docentes en todo el país. En la Universidad Nacional de Córdoba, el año 1946 concluyó con 161 docentes declarados "cesantes". ${ }^{8}$

8. (13 y 14 de noviembre de 1946). CBA. La FUC denunció que hasta el propio Bernardo Houssay fue “jubilado"; al año siguiente obtuvo el Premio Nobel de medicina. (27 de septiembre de 1946). La Voz del Interior 
La primavera de 1946 fue álgida. La FUC declaró un paro el 12 de septiembre y una huelga general de 72 horas en la última semana del mes. Entre noviembre y diciembre de 1946 el conflicto se agudizó. Un hecho fortuito estimuló la rebelión y la protesta satírica: al inaugurar la facultad de Filosofía de la UNC el rector interventor Felipe Pérez incurrió en un plagio del diccionario Espasa y de un libro del Dr. Rafael Bielsa, siendo descubierto in fraganti por estudiantes de la FUC. A partir de entonces el interventor Pérez fue llamado irónicamente "Espasa grande" y sus colaboradores "espasistas de bolsillo". ${ }^{9}$ La reputación de las autoridades universitarias había bajado hasta el zócalo. Empero, la lucha contra ellas era concebida como parte de un conflicto que trascendía los muros de la universidad. Tanto los análisis de la FUC como los de la Unión Demócrata Cristiana (agrupación católica liberal con base en la facultad de Derecho), estaban permeabilizados por el clima político intelectual derivado de la segunda posguerra mundial. De este modo, la acción gubernamental era interpretada en clave de un atropello "nazi fascista" contra las universidades. Por ello, la FUC llegó a sostener -en un documento dado a conocer el 9 de noviembre de 1946- que la crisis universitaria era "una crisis política de la nación” y convocó -en el lenguaje épico del antifascismo- a "la resistencia". ${ }^{10}$

Los incidentes tendieron a multiplicarse. $\mathrm{Si}$ por una parte, las autoridades aceptaban gustosas las renuncias de docentes disidentes (entre ellos, Arturo Orgaz) y se exoneraban empleados de la Biblioteca Mayor, por la otra, la FUC elaboraba listados de docentes colabora-

(LVI). HLC.

9. (4 y 10 de noviembre de 1946). CBA.

10.(9 de noviembre de 1946). CBA.

116 cionistas en cada facultad. ${ }^{11}$ El 2 de diciembre de 1946, una asamblea de alrededor de 1400 estudiantes celebrada en el estadio Córdoba Sport Club, decidió levantar la huelga. Pero los estudiantes resolvieron hacerse aplazar o "suspender" con un cero en los exámenes de fin de año, como expresión de protesta. ${ }^{12} \mathrm{La}$ intransigencia del activismo estudiantil fue respondida con violencia por elementos civiles adictos al gobierno nacional, quienes al parecer, contaron con complicidad policial. Entre el 10 y el 14 de diciembre de 1946 estallaron bombas (artefactos explosivos caseros) en los domicilios de tres docentes disidentes y de varios estudiantes contestatarios. La más importante estalló en el Comedor Universitario. La FUC señaló a los presuntos culpables: el "aliancismo aristocrático y nacionalista" es decir, la Alianza Libertadora Nacionalista (extrema derecha) y, en el caso del Comedor Universitario, al comisario de la seccional tercera de policía, sita en el corazón del estudiantil Barrio Clínicas. ${ }^{13}$

E1 modus operandi denunciado por la FUC era el siguiente: las bombas explotan en casas de estudiantes que luego son allanadas por la policía y detenidos sus ocupantes, es decir las víctimas de los atentados. Se denunció la existencia de 12 estudiantes detenidos y se responsabilizó de estas acciones a la policía en colaboración con grupos nazis. ${ }^{14}$

En junio de 1947, las autoridades universitarias no autorizaron la realización de elecciones de centros de estudiantes en los ámbitos físicos

11.(13 y 17 de noviembre de 1946). CBA.

12.(5 de diciembre de 1946). CBA. En términos españoles corrientes, bochar significa "suspender".

13. (13 y 14 de diciembre de 1946) (6 de enero de 1947). CBA.

14. (15 de diciembre de 1946). CBA. 
de la UNC. La correspondiente a la renovación del Centro de Estudiantes de Medicina se debió realizar en un baldío existente frente al Hospital de Clínicas, sobre la calle Santa Rosa; la de Ciencias Exactas se hizo en un local del Centro de Ingenieros y la de Derecho en un domicilio particular de la calle Obispo Trejo. ${ }^{15}$ Esto implicaba, de hecho, desconocer la legitimidad de los centros de estudiantes. Ese mismo mes, se prohibió el acto de conmemoración de la Reforma Universitaria. ${ }^{16}$ Pese a estas restricciones, a principios de julio, la asamblea de delegados de los distintos centros de estudiantes eligieron como secretaria general de la FUC a una mujer: Silvia Bermann. ${ }^{17}$

La ley 13.031, sancionada en la primavera de 1947, despejó las dudas: estableció que los rectores debían ser designados por el Poder Ejecutivo Nacional y que los consejos superiores de cada universidad debían ser integrados, exclusivamente, por el rector, los decanos y vicedecanos. En los consejos directivos de las facultades se admitió la participación estudiantil, pero esta debía estar limitada a un solo alumno elegido por sorteo entre los diez mejores promedios, con voz pero sin voto. $\mathrm{Al}$ año siguiente, al conmemorarse el 30 aniversario de la Reforma Universitaria, Alfredo Palacios graficó la situación: "La universidad renovada ha sido destruida, sólo quedan escombros”. ${ }^{18}$

15. (5 y 7 de junio de 1947). $C B A$.

16. (15 de junio de1947). $C B A$.

17. (2 de julio de 1947). $C B A$, Silvia era hija de Gregorio Bermann -referente intelectual del movimiento de la Reforma Universitaria de Córdoba y medico voluntario en la guerra civil española- $y$ hermana de Claudio, años después reconocido psicoanalista exiliado en Barcelona tras el golpe militar de 1976.

18. Discurso de Alfredo Palacios con motivo de una aniversario de la Reforma (1948) (mecanografiado).
A tenor de lo expuesto, cabe formular nuevos interrogantes: ¿La ley peronista aspiraba a despolitizar a las universidades? O, más bien ¿a politizarlas desde el Estado? Según recordó Gregorio Bermann, en 1946 el presidente Perón sostuvo "en el discurso a la Unión Sindical Universitaria en el teatro municipal de Buenos Aires, en el momento que precedió a la gran purga de profesores universitarios: "quiero que la política desaparezca de las universidades, porque si no hará desaparecer a las universidades". ${ }^{19} \mathrm{El}$ propósito enunciado, empero, distó de tener su correlato con la práctica política del oficialismo en el ámbito universitario. En 1945, había comenzado a gestarse, si bien tímidamente, un "sindicato de estudiantes universitarios" adepto a Perón..$^{20}$ En 1946, ya con el nombre de Sindicato Universitario de Córdoba (SUC) participó de un congreso nacional de estudiantes peronistas cuya agenda de discusiones estaba marcada por la relación entre "la juventud universitaria y la revolución nacional". Su proceso de organización interna concluyó en mayo de 1947 con la constitución formal del SUC. ${ }^{21}$

Paralelamente, el Poder Ejecutivo Nacional designó a los docentes que debían ocupar las cátedras vacantes por cesantías o dimisiones. Fue así, que los profesores designados viajaron a Buenos Aires para recibir en sus propias manos los diplomas en los que se acreditaba su nombramiento. ${ }^{22}$ De este modo, las desig-

AMRU.

19. Gregorio Bermann, Scherzo 1918, (mecanografiado), documento citato en p. 4 . El segundo entrecomillado es de Bermann.

20. (3 de julio de 1945). LPy (27 de septiembre de 1945). $L V I$.

21. (20 de mayo de 1947). CBA.

22. (20 de mayo de $1947 C B A$ 
naciones personalizaban el agradecimiento en la figura de Perón. Como corolario y punto de partida de una intensa homogeneización de la universidad en torno a la identidad peronista, el presidente Perón recibió, en febrero de 1948, el doctorado honoris causa de la UNC (Philp-Escudero, 2013). Se legitimaba, así, un bienio de expulsiones, prohibiciones y sanciones contra la disidencia estudiantil docente.

En 1948, se constituyó Unión Universitaria, agrupación presidida por Oscar Roger. Su autodefinición no dejaba lugar a equívocos: "somos profundamente católicos, eminentemente hispanistas y peronistas de convicción". Su devoción hispanista iba acompañada de cierto tufillo antisemita, así por ejemplo, acusaron públicamente al estudiante de ingeniería $\mathrm{Na}-$ talio Keyner de no ser argentino, pese a haber nacido en Argentina, "por insultar de frente o veladamente a la Madre Patria". ${ }^{23}$ En rigor, se remitía a una crítica a la dictadura de Franco.

En 1949, el Poder Ejecutivo Nacional suprimió las tasas que regían para la realización de actividades académicas (derechos de examen), pero luego los restableció parcialmente al imponer una multa de 30 pesos -el equivalente a comprar un diario a veinte centavos durante cinco meses consecutivos- por materia aplazada (Ferrero, 2005). De todas maneras, la medida pasó casi desapercibida en el marco de una dinámica política marcada por la polarización en el ámbito de la universidad. Ese mismo año se iniciaron los cursos de formación sindical

23. (19 de septiembre de 1948). CBA. La FUC: definió a la Unión Universitaria como "admiradores del tirano Franco, apologistas del hispanismo, traidores al contenido democrático y progresista de la Revolución de Mayo, apéndice dentro de la vida universitaria de un partido político". (27 de febrero de 1949). CBA. En 1949 el presidente de la FUC era Silvio Borioli.

118 que tenían por objeto uniformizar la universidad en torno al discurso peronista. Porque, paralelamente a la inclusión del tema gremial, se desató una virulenta oleada represiva contra los estudiantes que se movilizaban en solidaridad con la huelga de obreros azucareros tucumanos. Se produjeron numerosos allanamientos y 31 detenciones en Barrio Clínicas, entre ellas, la de José Lasalle, presidente del Centro de Estudiantes de Ingeniería. También se detuvo a numerosos estudiantes de farmacia y bioquímica. El dirigente estudiantil de la facultad de medicina, Samuel "Quichi” Kiezkowski, sufrió tres años de cárcel -puesto a disposición del PEN- a partir de entonces. ${ }^{24}$

En 1950, se constituyó la peronista Federación Gremial Universitaria, filial cordobesa de la Confederación General Universitaria (en adelante, CGU): su objetivo era preciso, barrer a la FUC. El afán de unanimidad era manifiesto. La Asociación Gremial de Estudiantes de Derecho solicitó al decano que "en lo sucesivo (...) establezca la prohibición absoluta de exhibir notas, panfletos, apuntes y demás propaganda efectuada por toda agrupación estudiantil que no sea esta Asociación Gremial”. ${ }^{25}$ En 1952, un nuevo paso en ese sentido fue dado por resoluciones decanales que limitaban el derecho a examen. La Juventud Socialista protestó porque en las facultades de Derecho e Ingeniería se exigía "certificado policial de buena conducta" como requisito indispensable para rendir exámenes a los integrantes de las

24. (21 de agosto de 1949, 3 de octubre de 1949 y 15 de diciembre de 1949). CBA y (2 de julio de 1953). LVI. El "Quichi", uno de los más relevantes cuadros estudiantiles de la época, formó parte, años después, de la experiencia de Pasado y Presente, orientada por José Aricó.

25. (2 de mayo de 1952). CBA. 
comisiones de centros de estudiantes. ${ }^{26}$ Ese mismo año, con motivo de cumplirse un nuevo aniversario de la Reforma Universitaria de 1918, el bloque peronista en la Legislatura de Córdoba se negó a rendirle homenaje, utilizando argumentos del universo clerical. El diputado Manuel Quero Matos fundamentaba:

porque la Reforma Universitaria traduce un sentido irreligioso de la vida y trasunta una total irreverencia a los principios más puros de la jerarquía y la nacionalidad. Por eso, señor presidente, y porque Dios siempre nos asiste, la Reforma Universitaria ya ha sido completamente derrotada al impulso de una juventud viril y auténticamente revolucionaria, que ha retomado definitivamente para la universidad el camino de Cristo y de la Patria. ${ }^{27}$

En 1953, una resolución rectoral (Horacio Ahumada había sucedido a José Urrutia a mediados del año anterior), dispuso que en la inauguración oficial de las clases, después del himno nacional debía cantarse la marcha peronista. ${ }^{28}$ Asimismo, se impuso una nueva exigencia para optar al cargo de practicante de hospital para los estudiantes de medicina: ser afiliados a la agrupación peronista, CGU. ${ }^{29}$ Ese mismo año, el aval presidencial a la uniformización de la universidad fue explícito: en septiembre de 1953, cuando Perón visitó Córdoba, pronunció un discurso en la sede de la adicta CGU. En 1954, se inauguraron en la

26. (3 de septiembre de 1952). LVI.

27. El homenaje había sido propuesto por el diputado radical Carlos Becerra. Cámara de Diputados de la Provincia de Córdoba. Diario de Sesiones (CDPCDS), 1952, p. 213 y 216. Biblioteca de la Legislatura de la Provincia de Córdoba (BLPC), Córdoba.

28. (19 de abril de 1953). LVI.

29. (16 de junio de 1953). LVI. facultad de Ciencias Económicas los cursos de "formación política y doctrina nacional", de acuerdo con la ley universitaria $\mathrm{N}^{\circ} 14297$. Antonio Carreras Allende, vicedecano en ejercicio del decanato de Económicas expresó que se trataba de superar "la posición liberal, neutral y agnóstica de la vieja UNC" ${ }^{30} \mathrm{~A}$ tenor de lo expuesto, se comprende que la caída del presidente Perón por un golpe militar en 1955, fuese recibida con júbilo por el movimiento reformista.

\section{Nacionalismo y reformismo tras el exilio de Perón}

Tras 18 años de exilio -la mayor parte de ellos en España- Perón regresó definitivamente a la Argentina en 1973, luego del triunfo electoral que consagró a Héctor Cámpora -uno de sus más fieles epígonos- como presidente del país. Gobernó durante un período de 49 días, tras los cuales renunció y se convocaron a nuevas elecciones que permitieron el acceso a la presidencia del propio Juan Perón. Durante el trienio peronista (1973-1976), la educación superior fue objeto de intensas controversias.

La Universidad, en la administración de Héctor Cámpora, -pero también durante la presidencia de J.D. Perón- fue uno de los espacios en que mayoritariamente la izquierda peronis-

30.(2 de agosto de 1954). CBA. cabe señalar que en 1954 la Federación Gremial Universitaria, filial cordobesa (FGU) de la CGU tenía como presidente a José Cortiñas (Medicina) y como secretario general a Sánchez Freytes

(Derecho). Asimismo participaba activamente en la política interna del peronismo: la FGU apoyó como candidato a senador provincial por el departamento Santa María a Julio Antún, quien integró la primera comisión directiva de la asociación gremial de estudiantes de Derecho. Véase: (16 de febrero de 1954 y 7 de marzo de 1954). $C B A$. 
ta hizo sentir su ascendencia, en parte por las negociaciones llevadas adelante con los otros sectores del peronismo, pero también como consecuencia de la radicalización de la vida universitaria durante la Revolución Argentina entre 1966-1973 (Dip, 2012).

La designación de los interventores universitarios contó con el respaldo de la Juventud Universitaria Peronista (en adelante, JUP), hegemonizada por Montoneros y expresión mayoritaria estudiantil. La efervescencia política en las universidades, proceso que venía gestándose desde tiempo atrás, tendió a disolver el campo estrictamente académico-científico, diluyéndose los contornos del trabajo científico y la militancia política. La reacción de los diferentes actores de la derecha peronista y del nacionalismo católico se encuadró en consecuencia, en la denuncia de la infiltración marxista en la dirección de las casas de altos estudios, desacreditando los méritos intelectuales de los nombrados, y encauzando su accionar por todas las vías posibles ${ }^{31}$ para modificar una correlación de fuerzas claramente adversa.

Tras la redacción del Documento Reservado del 1 de octubre de 1973 emitido por el Consejo Superior del Movimiento Nacional Justicialista y respaldado por Perón (como se citó en Franco, 2012), los grupos ortodoxos y de derecha vieron la oportunidad de disputar un espacio reservado hasta entonces al ala izquierda del peronismo.

Tanto el semanario El Caudillo de la Tercera Posición (en adelante, EC), expresión orgánica

31. Véase el accionar de Concentración Nacional Universitaria, fundamentalmente en la Universidad Nacional de Mar del Plata y la Universidad Nacional de La Plata. (6 de diciembre de 2011). La Capital. Mar del Plata de la Juventud Sindical Peronista -financiada con aportes del Ministerio de Bienestar Social conducido por José López Rega-, como Marchar, dirigido por Guillermo Patricio Kelly o Leña, del agrupamiento autodenominado $\mathrm{Na}-$ cionalsindicalismo, de Luis Bandieri, confrontaron abiertamente con la política universitaria gubernamental. La mirada de estos semanarios sobre la universidad, a la que veían como un baluarte hegemonizado por el marxismo, le subyacía una crítica más radical, que se superponía y trascendía la lucha política coyuntural. En el diagnóstico efectuado por estos sectores, cuyo común denominador era el nacionalismo, la Reforma del 18, sus valores democratizadores y liberales, constituían la tradición a disolver, volcando todos sus esfuerzos a ello.

Estas publicaciones compartieron un nacionalismo reaccionario, un feroz anticomunismo y antisemitismo, identificando a Perón con el caudillo capaz de encarnar y llevar adelante la comunidad organizada, superadora de las formas de la democracia burguesa y del socialismo. Sin embargo, hay trazos que las distinguen. La revista Leña se inscribió en las coordenadas de un nacionalismo católico ultramontano e hispanista, mientras que Marchar ofreció un perfil nacionalista en que la religión distó de ocupar una dimensión central. $E C$, en cambio, respondió a una formación netamente peronista, aún cuando su director y los periodistas que la hicieron posible, también reconocieron en el falangismo español (como los redactores de Leña) una fuente doctrinaria. Los tres emprendimientos editoriales abrevaron en una concepción del poder fuertemente jerárquica y verticalista, fundado en la exaltación al valor personal, la acción directa y la noción de jefatura. La designación de Rodolfo Puiggrós como rector interventor de la Universidad Nacional de Buenos Aires, la más grande del país, fue 
interpretada por la derecha peronista en clave de amenaza y afrenta y en consecuencia, en un espacio más para dirimir la lucha interna.

\section{La Universidad bajo el signo de un nacionalismo de izquierda}

El proyecto de reforma de la universidad propiciado por Puiggrós (1974) apuntaba a integrarla en clave nacionalista:

desde mi punto de vista, la discusión de si la universidad debe ser privada o estatal es una discusión ociosa, porque lo fundamental es que toda universidad (...) refleje su enseñanza en la doctrina nacional e impida la infiltración de liberalismo, del positivismo, del historicismo, del utilitarismo y yo diría hasta del desarrollismo, todas formas con las que se disfraza la penetración ideológica en las casas de estudio (p. 274).

También promovía la discusión de los planes de estudio de las carreras pero como una atribución del estado, en tanto, lo que estaba en juego era una cuestión de "soberanía nacional”. En otros términos, la universidad debía ser puesta al servicio del proceso nacional y, en consecuencia, eliminada su autonomía. En la misma dirección sostenía que "los profesores van a ser sometidos a la consideración de los estudiantes y de los postulados de la doctrina nacional y popular" (1974, p. 56) estableciéndose incompatibilidades para los docentes que tuvieran vinculaciones con empresas multinacionales.

Una de las primeras medidas adoptadas por el rector interventor fue la restitución del título de Dr. Honoris Causa a Perón y el decreto de reincorporación a los docentes cesanteados en
1955, decisiones muy sentidas por las distintas facciones del peronismo. Estas acciones de reposición de derechos fue acompañada por medidas de impacto simbólico como la designación en carácter de "eméritos de la Patria y profesores honorarios post-mortem" a Eva Perón, Ramón Carrillo, Raúl Scalabrini Ortiz y John William Cooke, entre otros, ${ }^{32}$ lo que evidenciaba que más que un proyecto científico, de lo que se trataba era de poner en primer plano el peso de la tradición nacional-popular en las nuevas bases de la política universitaria.

La gestión Puiggrós impulsó también la cátedra obligatoria de "Historia social de las luchas del Pueblo Argentino" para todos los estudiantes de la UBA; la que fue renominada como Universidad Nacional y Popular de Buenos Aires. También se impulsó la extensión universitaria, con iniciativas novedosas como la fabricación de medicamentos, o la realización de tareas de prevención de la salud en distintas poblaciones desfavorecidas, entendiendo que la formación profesional debía ser puesta al servicio de los sectores populares. Todas estas iniciativas contaron con una fuerte adhesión estudiantil, principalmente de la JUP.

Si bien Puiggrós era anatemizado por la derecha peronista como el símbolo de la avanzada marxista en la universidad, las designaciones de los cargos en las distintas Facultades fue más la resultante de negociaciones y expresión de las realidades políticas de cada uno de los espacios, que un proyecto acabado (Friedemann, 2018). En cambio, el antiliberalismo, el cuestionamiento de la autonomía universitaria y de la libertad de cátedra fueron tra-

32. (26 de Julio de 1973). Militancia Peronista para la Liberación $(M P L)$ 7, p. 19. Recuperado de http://www. ruinasdigitales.com/militancia-peronista/listado-denumeros/ 
zos compartidos por todos los actores de ese universo político antagónico, que embarcados en un proyecto de transformación radical de la sociedad -ya fuera en clave revolucionaria o reaccionaria- habían subsumido el campo científico e intelectual a los fragores de la lucha política. Si en un principio la influencia de Puiggrós se extendió a otras universidades del país, su temprana renuncia anticipó el cambio de correlación de fuerzas de la coyuntura.

\section{El nacionalsindicalismo}

La revista Leña, vocero del nacional-sindicalismo, grupo nacionalista y católico, fue una publicación quincenal, relativamente artesanal. Su primer número apareció la segunda quincena de julio de 1973. Tras la masacre de Ezeiza denunciaban la infiltración de la izquierda en el peronismo. A su juicio, ésta buscaba el magnicidio de Perón para desencadenar una "guerra civil". 33

Para este sector, la Reforma de 1918, instaló la decadencia de la universidad argentina, desde la avanzada de un liberalismo que había destruido orden y jerarquía encarnadas por los curas. Esa introducción servía para establecer un paralelismo entre la universidad de ayer y la de 1973. Para los redactores de Leña, que graficaban sus páginas con el lema Dios, $\mathrm{Pa}$ -

33.E1 20 de Junio de 1973 ante el regreso definitivo de Juan D. Perón al país hubo una multitudinaria manifestación que culminó con cientos de muertos y heridos. Las crónicas periodísticas hablaron de "choques" entre distintos sectores peronistas por el control del palco central. La tendencia revolucionaria documentó en sus publicaciones la agresión sufrida por parte de bandas armadas pertenecientes a los sectores de la derecha sindical y la contratación de "mercenarios" (Bonasso, 1997).

122 tria y Hogar, la Universidad, comandada por el "tovarich (Roberto) Puiggrós" -alusión a su temprana militancia en el Partido Comunistalejos de levantar los ideales de la universidad nacional pergeñada durante el peronismo de los años cuarenta, había abierto las puertas al marxismo que "no es sino la radicalización más extrema del liberalismo. El reformismo liberal, comenzó a hacer causa común con el reformismo marxista", ${ }^{34}$ denunciaban. El cuestionamiento a la reforma de 1918 pasaba por varios ejes. Por un lado, la destrucción de autoridad $\mathrm{y}$ tradición sostenida por los curas. En segundo lugar, consideraban que la reforma era una avanzada del liberalismo, que no sólo había destruido "la patria criolla" sino que era causante de dependencia. ${ }^{35}$ Además, la autonomía reformista, era acusada de generar aislamiento ante los problemas y sentires populares. El argumento subyacente, residía en el deber indelegable del Estado por fijar las prioridades y dirección de la educación y en este sentido, la selección de su personal. Por ello, postulaban la vigencia de la Ley 13031 de 1947, en la que el Poder Ejecutivo regulaba en detalle la vida de las universidades y las direccionaba doctrinariamente.

En el número 2 de Leña, la referencia a la universidad se mantuvo a nivel de consignas y denuncias a la infiltración de las universidades. El tono, sin embargo, se tornó más violento. En las últimas páginas, en una sección titulada "Leña a Palos" (dirigida a legisladores que no reclamaban una amnistía para la memoria de los próceres del nacionalismo y "Leña a Tiros"

34. (segunda quincena de Julio de 1973. Leña. Vocero Nacional Sindicalista (LVNS), p. 3. Recuperado de http:// www.ruinasdigitales.com/

35.(segunda quincena de Julio de 1973. Leña. Vocero Nacional Sindicalista, p. 3. 
dirigida al Ministro de Educación Jorge Taiana, instaban a la violencia contra quien adjetivaban como "zurdo entregador" y acusaban de "usurpar dos gobiernos peronistas para servir al marxismo". En esta lista se sumaba a Puiggrós, Mario Kestelboim y otras figuras prominentes de la Universidad de Buenos Aires.

Su crítica apuntaba a identificar en la Reforma de 1918 con sus aires de renovación libertaria y democrática, la piedra angular de la alienación de los sectores profesionales argentinos, enfermos de liberalismo y marxismo. En su esquema reaccionario, nación y catolicismo eran las bases en las que abrevar para reconstruir el país.

\section{La derecha peronista}

En noviembre de 1973, con Juan Domingo Perón al frente de la Presidencia de la Nación vio la luz pública $E C$; semanario de la derecha peronista. El financiamiento partió del Ministerio de Bienestar Social, a cargo de José López Rega -ministro de esa cartera y secretario privado del General Perón- y contó con el respaldo del Consejo Superior del Movimiento Nacional Justicialista. ${ }^{36}$

En sus páginas se observa publicidad oficial: Ferrocarriles Argentinos, Banco Nación; Lotería; Banco Social de Córdoba y solicitadas de Sindicatos afines a la línea editorial y del propio CSMNJ. El asesinato del secretario general de la Confederación General del Trabajo (CGT), José Ignacio Rucci, parece haber sido el desencadenante para invertir en una

36.(5 de mayo de 2014), Tiempo Argentino. (7 de enero de 2007). Página 12. publicación que coadyuvara a legitimar la "depuración” interna emanada por el Documento Reservado ${ }^{37}$ emitido por el cuerpo colegiado.

La publicación fue un semanario de información general, dirigido por Felipe Romeo ${ }^{38}$ y concebida como "trincheras al servicio de la militancia revolucionaria peronista". ${ }^{39}$ Felipe Romeo provenía de la Guardia Restauradora Nacionalista, y fue admirador del falangismo español, con el que mantuvo estrechos vínculos, especialmente con su brazo universitario. $E C$ era una publicación para-estatal, que articulaba a una derecha peronista mucho más amplia que la expresada en clave de clericalismo. Se presentaba como la representación del peronismo, del "verdadero peronismo".

Desde su mirada, "la sublevación reformista-marxista de 1918 y la destrucción sinárquica de 1955 marcan dos hitos ineludibles en el proceso de desmovilización de la inteligencia nacional". ${ }^{40}$ De este modo, aceptar la universidad democrática y reformista suponía minar al Estado Nacional por dentro: crear un estado dentro del estado.

Para el universo cultural de los redactores de $E C$, las cesantías a los docentes peronistas y la

37. El “Documento Reservado", presentado por Perón a los Gobernadores el 1 de octubre de 1973 fue una declaración emitida por la plana mayor del Consejo Superior del Movimiento Nacional Justicialista, en la que se daban expresas instrucciones para depurar las filas justicialistas de la infiltración marxista.

38. Durante 10 números la publicación estuvo a cargo de Enrique Gerez de la Juventud Peronista de la República Argentina (en adelante, JPRA). Posteriormente Gerez fue aparatado y descalificado públicamente por el semanario por "graves desviaciones ideológicas".

39.(7 de junio de 1974). El Caudillo de la Tercera posición $(E C), 30$. http://www.ruinasdigitales.com/el-caudillo/

40. (27 de septiembre de 1974). EC 45, p. 21 
puesta en vigencia de la autonomía universitaria tras el derrocamiento de Perón, constituyeron un inadmisible proceso de derrumbe, en tanto que abrieron sus puertas al liberalismo y el marxismo, que contaminaron con ideas foráneas e individualistas a la juventud. Reivindicaban a la universidad peronista, que encuadraba a los jóvenes "en organizaciones orientadas por el Estado (...). [En ellas] la juventud era formada en el marco de una comunidad organizada, con objetivos claros y en función de una doctrina y una teoría con propósitos definidos". ${ }^{41} \mathrm{La}$ condena a la política universitaria tenía dos frentes de confrontación; por un lado los sectores reformistas y cientificistas, pero también la intervención de la gestión de Cámpora -y sus designaciones al frente de la UBA- a la que señalaban como la consumación de la "descomposición" de la educación superior, identificando el avance de los sectores peronistas de izquierda en la conducción como "parte vital del proceso de desnacionalización". Lo que estaba en discusión era, en definitiva, la subordinación de la educación superior al proyecto político peronista.

$E C$ denunciaba, por un lado, que la universidad había devenido en "una poderosa estructura con la que se ha ido plasmando un sentido profesionalista, individualista, signado por una filosofía práctica, utilitaria y pragmática de definida orientación materialista", al tiempo que cuestionaba centralmente la pérdida de rigor académico, la carencia de valores nacionales, la falta de disciplina y autoridad.

El modelo universitario del peronismo ortodoxo era expresado como "el órgano específico de la comunidad organizada" cuyos objetivos involucraban la investigación de nuevos cono-

41. (7 de diciembre de 1973). EC 4.

124 cimientos, pero también la conservación y difusión del saber cultural y científico, además de la transmisión de los valores éticos y estéticos constitutivos de la nacionalidad. ${ }^{42}$

La designación al frente del Ministerio de Educación de Oscar Ivanissevich y el nombramiento de Alberto Ottalagano como rector interventor de la UBA, durante el gobierno de Estela Martínez, contó con el caluroso entusiasmo del equipo periodístico, que encontró en ellos interlocutores en sintonía ideológica y un equipo dispuesto a realizar una depuración de "infiltrados marxistas" y liberales. Los referentes intelectuales mencionados fueron una mezcla de nacionalistas de distintas vertientes: desde el nacionalismo pro-fascista de Gustavo Martínez Zuviría (Hugo Wast), ${ }^{43}$ al nacional-popular de Raúl Scalabrini Ortiz (1940).

\section{La Alianza Libertadora Nacionalista}

La revista Marchar, dirigida por Miguel Sweck y Humberto Guidi era vocera de la Alianza Libertadora Nacionalista, la fracción liderada por Guillermo Patricio Kelly. Desde la mirada de esta publicación nacionalista, el rector nombrado por Cámpora al frente de la UBA, Puiggrós, había vaciado los estudios superiores del contenido técnico y científico necesario para el desarrollo del país, suplantándolo por "un contrabando ideológico (...) que sustituyó el estudio por la deliberación". ${ }^{44}$ Para este sec-

42. (7 de diciembre de 1973). EC 4.

43. Entre sus obras más profundamente antisemitas se encuentran 666 de 1942, Recuperado de https://es.scribd. com/doc/112030895/Hugo-Wast-Juana-Tabor-666 y Kahal y Oro de 1935. En línea https://es.scribd.com/ doc/36533215/Hugo-Wast-Kahal-y-Oro .

44. (octubre de 1974). Marhar (Mar) 1. Recuperado de http://www.ruinasdigitales.com/marchar/ 
tor, la libertad de pensamiento era admisible, pero fuera de las cátedras. Asimismo, acusaba a Puiggros de una trayectoria sinuosa: haber trabajado en los años cuarenta en el Partido Comunista, del que luego fue expulsado por haber integrado la Secretaría del Comandante Solveira Casares, responsable de la vigilancia de las actividades comunistas durante el primer gobierno de Perón. Esta recurrencia a archivos de inteligencia constituyó una modalidad también presente en $E C$, lo que habilita a preguntarse sobre los vínculos existentes entre estos colectivos y los archivos de los servicios de información del estado.

La postura de Marchar en relación a la universidad compartía la caracterización clásica del peronismo. Sostenía que la Universidad había sido una isla, y en consecuencia "baluarte de toda ofensiva reaccionaria”. El eje estaba puesto en las opciones políticas que la universidad asumió a partir de 1930. En esta narrativa se sostenía que la universidad fue la avanzada del derrocamiento de Hipólito Yrigoyen. "Los estudiantes de ese entonces, en nombre de Marx, Lenin y Stalin hacían cola en 'Crítica" para entregar sus comunicados contra la "dictadura”. Señalaban la incomprensión de los estudiantes en 1945 ante el fenómeno de Perón, jugando con la dicotomía de clase graficada como "los proletarios de rostros curtidos" frente a los "jóvenes de caras descansadas". Luego remitía a 1955 y el apoyo de los estudiantes al derrocamiento de Perón. Señalaba la nota que el movimiento estudiantil había sido instrumentalizado por los sectores dominantes para perseguir sus propios fines y luego, habían sido desechados. Y planteaba que los alineamientos estudiantiles de 1974 mantenían una continuidad histórica con la tradición antinacional. ${ }^{45}$

45. (octubre 1974). Marchar 2.

\section{Reflexiones finales}

Con la breve excepción de FORJA, el nacionalismo fue un antagonista del reformismo universitario. El antimperialismo del movimiento reformista constituyó un puente trunco con las posturas nacionalistas. Los intelectuales reformistas propiciaron -al igual que los nacionalistas- que los recursos naturales de los pueblos de América Latina -como el petróleono fuesen enajenados a las grandes potencias extranjeras de la época. Pero propuestas de esta índole se engarzaban en un arco iris de filones de pensamiento que repugnaban al ascendiente nacionalismo de derecha de las décadas del veinte y el treinta, así como al peronismo de los años cuarenta, cincuenta y aún de los setenta: sus vetas heterodoxas se asociaban a un universo cultural que incluía elementos marxistas, liberales, masonas, feministas, georgistas y del pacifismo antimilitarista.

Para la cultura reformista, el ideal americanista trascendía el Estado-nación. De allí, la aseveración que aparecía en la tapa del número 13 de La Gaceta Universitaria: hay solo dos patrias: "la patria de los privilegiados y la patria de los desposeídos". ${ }^{46} \mathrm{El}$ culto a la virilidad masculina y la retórica patriotera estaban fuera de sus registros básicos. Así se explica la gestación del Comité Femenino de Córdoba Libre o el apoyo brindado por el periódico de los estudiantes de la Reforma a la Asociación Feminista Nacional, o más aún, la presencia de vetas masonas a través del Comité de Libre Pensamiento (Tcach, 2008).

E1 nacionalismo, a su vez, construyó su posición anti-reformista en cuatro registros que descansaron en un sustrato común: la defensa

46. (4 de julio de 1919). $L G U$ 13, p.1. 
de una tradición que exaltaba a la Iglesia y al Ejército como los fundadores de la Patria (clave tradicionalista); la contraposición entre las masas y los sectores medios que habían gestado la Reforma (clave plebeya); el anti-intelectualismo (clave xenófoba que se vinculaba a la denuncia de lo extranjero), y el imperativo de incluir a las universidades en un entramado organicista marcado por el primado de la cohesión, la "Comunidad Organizada" (clave peronista). El común denominador que asociaba estas cuatro miradas era el antiliberalismo, en el sentido político-cultural de la expresión. La heterofobia política permitió concebir a la Reforma cordobesa del 18 como una semilla: el origen de la subversión, de la desnacionalización de las ideas y las costumbres, como una suerte de caja de Pandora que expandió sobre las universidades todos los males del universo.<smiles>C=C[Te]=C</smiles>

Recibido: 05-09-2018

Aceptado: 19-03-2019

Publicado: 04-06-2019 


\section{Referencias Bibliográficas}

Baschetti, R. (1999). Documentos. 1973-1976. De la ruptura al Golpe (Vol. 2). Buenos Aires: De la Campana.

Bonasso, M. (1997). El Presidente que no fue. Los archivos ocultos del peronismo. Buenos Aires: Paidós.

Bustelo, N. (2018). Reforma Universitaria y feminismo. La tinta. Recuperado de https://latinta.com. ar/2018/06/vidas-y-andanzas-reforma-universitaria-feminismo

Dip, N. (2012). Peronismo y Universidad en los años sesenta. Una aproximación a las tramas discursivas y organizativas del proceso de peronización de los sectores estudiantiles y docentes de la Universidad de Buenos Aires (1966-1973). Cuestiones de Sociologia, 8, Recuperado de https://www.cuestionessociologia. fahce.unlp.edu.ar/article/view/CSn08a22/4344

Ferrero, R. (2005). Historia critica del movimiento estudiantil (Vol. 2). Córdoba: Alción

Franco, M. (2012). Un enemigo para la Nación. Orden interno, violencia y subversión. 1973-1976. Buenos Aires: Fondo de Cultura Económica.

Friedeman, S. (2018). “Compañeros decanos”. La reforma universitaria de la izquierda peronista a través de las designaciones de autoridades en la Universidad de Buenos Aires (1973-1974). Polbis, 11(21), 162200. Recuperado de http://polhis.com.ar/index.php/PolHis/article/view/279/505081

Hernández Arregui, J. J. (1973). La formación de la conciencia nacional. Buenos Aires: Plus Ultra.

Montenegro, A. (1984). Saúl Taborda. Buenos Aires: Ediciones Culturales Argentinas.

Moyano, J. (2004). El concepto de América Latina en el pensamiento de Manuel Ugarte y Deodoro Roca. En A. Granados García y C. Marichal (Comps.), Construcción de las identidades latinoamericanas. Ensayos de Historia Intelectual (siglos XIX y XX) (pp. 179206) México: El Colegio de México. Recuperado de https://www.jstor.org/stable/j. ctv3f8ntm.9? refreqid=excelsior\%3A079f83f83057cc245de2da54dcf3509b\&seq=1\#metadata_info_ tab_contents

Philp, M. y Escudero, E. (2013). Dos doctores honoris causa de la Universidad Nacional de Córdoba: una lectura de los vínculos entre universidad y política. En D. Saur y A. Servetto (Coords.), Universidad Nacional de Córdoba. Cuatrocientos años de historia (Vol. 2) (pp. 211-229). Córdoba: Universidad Nacional de Córdoba.

Puigros R. (1974). La Universidad del Pueblo. Buenos Aires: Crisis.

Roca, D. (2006). Reformismo y antimperialismo. Buenos Aires: Grupo Editor Universitario.

Roitenburd,S.(2007).La hora de América en un horizonte de reforma: Saúl Taborda:un intelectualalternativo. E-l@tina, 5(18), 11-31. Recuperado de https://www.redalyc.org/articulo.oa?id=496451233002 
Scalabrini Ortíz, R. (1940). Politica británica en el Rio de la Plata. Buenos Aires: Editorial Lancelot.

Taborda, S. (1918). Reflexiones sobre el ideal político de América. Córdoba: Imprenta La Elzeviriana.

Tcach, C. (2008). De la monotonía de los claustros a la polifonía de las ideas: Introducción a La Gaceta Universitaria. En M. Candelari, C Tcach y M. C. Bravo. La Gaceta Universitaria 1918-1919. Una mirada sobre el movimiento reformista en las universidades nacionales. Buenos Aires: Eudeba.

Tcach, C. (2016). Movimientismos en perspectiva comparada: peronismo y radicalismo yrigoyenista. Perfiles Latinoamericanos, 24(48), 61-82. Recuperado de http://www.scielo.org.mx/scielo. php?script=sci_arttext\&pid=S0188-76532016000200061 